\title{
Fisonomía y diversidad del bosque secundario de Prosopis caldenia. Provincia de la Pampa, Argentina
}

\author{
Appearance and Diversity of Secondary Forest of Prosopis \\ Caldenia. La Pampa Province, Argentina
}

\author{
Valeria S. Duval ${ }^{1}$ \\ Graciela M. Benedetti ${ }^{2}$ \\ Alicia M. Campo ${ }^{3}$ \\ Universidad Nacional del Sur, Argentina
}

\begin{abstract}
Resumen
El bosque de caldén (Prosopis caldenia) es una formación vegetal endémica de la Argentina distribuido, principalmente, en la provincia de La Pampa. El valor económico de la madera del caldén fue una de las causas por las que este bosque esta actualmente degradado y fragmentado. Es por ello, que la existencia de áreas protegidas que preserven esta masa forestal es fundamental para su conservación. El objetivo del trabajo fue analizar la fisonomía y diversidad de la vegetación en el bosque de caldén en la Reserva Provincial Parque Luro, provincia de La Pampa, Argentina. Para ello, se aplicaron metodologías de relevamiento de vegetación, índices de diversidad, valor de importancia y NDVI. Los resultados mostraron un cambio de fisonomía en relación con el bosque prístino. Se reconoce que el estrato arbustivo adquirió mayor cobertura, aunque el caldén continúa siendo la especie con mayor valor de importancia en el bosque.
\end{abstract}

Palabras clave: endémico, bosque de caldén, áreas protegidas, biodiversidad.

1 Dra. Universidad Nacional del Sur, 12 de Octubre y San Juan, Bahía Blanca. CONICET. Correo electrónico: valeria.duval@uns.edu.ar

2 Mg. Universidad Nacional del Sur, 12 de Octubre y San Juan, Bahía Blanca. Correo electrónico: gbenedet@ criba.edu.ar

3 Dra. Universidad Nacional del Sur, 12 de Octubre y San Juan, Bahía Blanca. CONICET. Correo electrónico: amcampo@uns.edu.ar 


\begin{abstract}
The calden forest (Prosopis caldenia) is an endemic vegetation formation of Argentina, mainly distributed in the province of La Pampa. The economic value of the calden wood was one of the reasons why this forest is currently degraded and fragmented. That is why the existence of protected areas to preserve this forest mass is fundamental for its conservation. This work aimed to analyze the appearance and diversity of vegetation in the calden forest, in Luro Park Provincial Reserve, La Pampa province, Argentina. To do this, we applied methodologies of studying vegetation, diversity indices, values of importance and NDVI. The results showed a change of appearance in relation to the pristine forest. It is recognized that the shrubby stratum acquired greater coverage, although the calden continues to be the species with the highest value of importance in the forest.
\end{abstract}

Keywords: Endemic, calden forest, protected areas, biodiversity.

\title{
Introducción
}

La fitogeografía es una rama de la Biogeografía que tiene como objeto de estudio la distribución de las plantas en el espacio y las causas que lo explican. Uno de sus enfoques es el fisionómico-dinámico que propone una metodología para abordar los estudios sobre la cobertura vegetal a través del tiempo en relación con los factores externos que la influyen. La vegetación refleja en su forma y su distribución las complejas relaciones que posee con los elementos abióticos y bióticos que la rodean (Benlloch y Yetano Ruiz, 1989; Sala Sanjaume y Batalla Villanueva, 1996). Las transformaciones en el paisaje natural, producto de la intervención de la sociedad, plantea la necesidad de reconocer los cambios fisonómicos y estructurales de la flora. Es por ello, que en las últimas décadas se han incrementado las investigaciones en los bosques nativos de la Argentina.

El bosque de caldén es un distrito que se ubica en el Espinal, una provincia fitogeográfica de la Argentina. Cabrera (1976) estableció su localización en las provincias de Córdoba, La Pampa, San Luis y Buenos Aires. Este bosque fue estudiado por diversos autores, entre ellos se mencionan Lell (2005), Lerner (2005), Dussart et al. (2011), Lewis et al. (2007), Bogino (2006) y Medina (2007, 2008). Estas investigaciones siguen distintas temáticas de análisis como su fisonomía, su valor económico y los problemas detectados relacionados con la degradación, la pérdida de vegetación y la dinámica del fuego.

Se caracteriza por tener como representante el Prosopis caldenia, árbol caducifolio de una altura promedio de $12 \mathrm{~m}$ que es endémico a nivel mundial, ya que no se encuentra en el resto del planeta. Otros árboles representantes del bosque que lo acompañan son Prosopis flexuosa (algarrobo), 
Valeria S. Duval, Graciela M. Benedetti, Alicia M. Campo. Fisonomía y diversidad del bosque secundario de Prosopis caldenia. Provincia de la Pampa, Argentina

Geoffroea decorticans (chañar) y Jodina rhombifolia (sombra de toro). El estrato arbustivo es variable, tiene una cobertura media y se identifican, entre otras especies, Condalia microphylla (piquillín), Lycium chilense (yaoyín) y Aloysia gratissima (azhar del monte). El estrato herbáceo es el más pobre y se caracteriza por la existencia de gramíneas teniendo como géneros predominantes, Stipa y Poa.

Desde tiempos pasados, el caldén fue una especie sagrada para los ranqueles, pueblo originario de la Argentina. El caldenal prístino estaba compuesto por el estrato arbóreo y el herbáceo cuya fisonomía era similar al bioma de la sabana. Posteriormente, la valorización de la madera del caldén a través de la actividad forestal y la expansión de la frontera agropecuaria generaron un empobrecimiento del bosque (Lencinas et al. 2006). Como consecuencia, el bosque secundario se encuentra degradado y fragmentado, situación que se observa en su estructura y fisonomía actual. Además, se incorpora el estrato arbustivo el cual presenta un porcentaje de cobertura elevado.

En el año 2007, fue aprobada la ley de presupuestos mínimos de protección ambiental de los bosques nativos (Ley Nacional 26331). En este contexto, en La Pampa se sancionó la ley 2624, aprobando la ley de Ordenamiento Territorial de Bosques Nativos antes mencionada, en la cual se definieron los sitios de mayor preservación que deberían poseer categoría I. La Reserva Provincial Parque Luro es una de estas áreas, por lo cual se estableció la prohibición del desmonte y la extracción de madera en su interior. Este espacio protegido es la porción de bosque nativo más grande de la provincia, y es por ello, que se creó con el objetivo de conservar su vegetación. Bajo la figura de protección, el bosque no fue alterado, así como tampoco se realizaron tareas de restauración, según como lo indica la legislación. A fin de conocer las características del bosque secundario, el objetivo del presente trabajo fue analizar la fisonomía y diversidad del bosque de caldén en la Reserva Provincial Parque Luro, provincia de La Pampa, Argentina.

\section{Área de estudio}

Para el estudio de esta ecorregión argentina se tuvo en consideración la Reserva Provincial Parque Luro, un área protegida que se creó en 1996 con el objetivo de conservar el bosque de caldén (Figura 1). Esta se localiza 
en el centro-este de la provincia de La Pampa (Argentina) y posee 7.608 ha, es de jurisdicción provincial y actualmente es la porción de caldenal más grande del distrito del caldén. El clima es templado con temperaturas máximas superiores a $35^{\circ} \mathrm{C}$ en verano y temperaturas mínimas de $-8{ }^{\circ} \mathrm{C}$ en invierno. La precipitación media anual es de $676 \mathrm{~mm}$, registrándose la mayor cantidad durante los meses de octubre y noviembre.

\section{Materiales y métodos}

Los métodos utilizados para la identificación de las características de la comunidad vegetal fueron: a) muestreo en transecto de formaciones vegetales de fanerófitos y caméfitos, b) el Índice de Vegetación Estandarizada, c) índices de diversidad e d) Índice de Valor de Importancia.

El muestreo en transecto de formaciones vegetales de fanerófitos y caméfitos tiene como objetivo principal caracterizar la dinámica geobotánica de las formaciones vegetales de fanerófitos y caméfitos. Se centra en su estructura vertical-horizontal y su fisonomía, así como los factores que explican su distribución. Además, identifica las formaciones vegetales como unidades fisonómico-estructurales-fenológicas. Como resultado de la aplicación de los transectos se elaboraron los Diagramas de Burbujas que muestran la distribución de los individuos vegetales y la distancia a la izquierda o derecha al transecto principal. Por otra parte, se realizó el Diagrama Ecodinámico de Riqueza-Estructura-Cobertura que es producto de la cobertura vegetal, y en el cual las especies se clasificaron en 4 estratos arbóreos (A), 2 arbustivos (ab), 1 subarbustivo (s_ab) y 1 herbáceo (h). El ancho de cada categoría lo establece el número de especies y la cobertura se representa como una trama dentro de cada barra. La misma se agrupa en 6 clases: de 0 a 15 $\%, 16$ a $30 \%, 31$ a $45 \%, 46$ a $60 \%, 61$ a $75 \%$ y > a $75 \%$. 
Valeria S. Duval, Graciela M. Benedetti, Alicia M. Campo. Fisonomía y diversidad del bosque secundario de Prosopis caldenia. Provincia de la Pampa, Argentina

Figura 1. Localización del bosque de caldén en la Argentina (A) y de la Reserva Provincial Parque Luro (B).
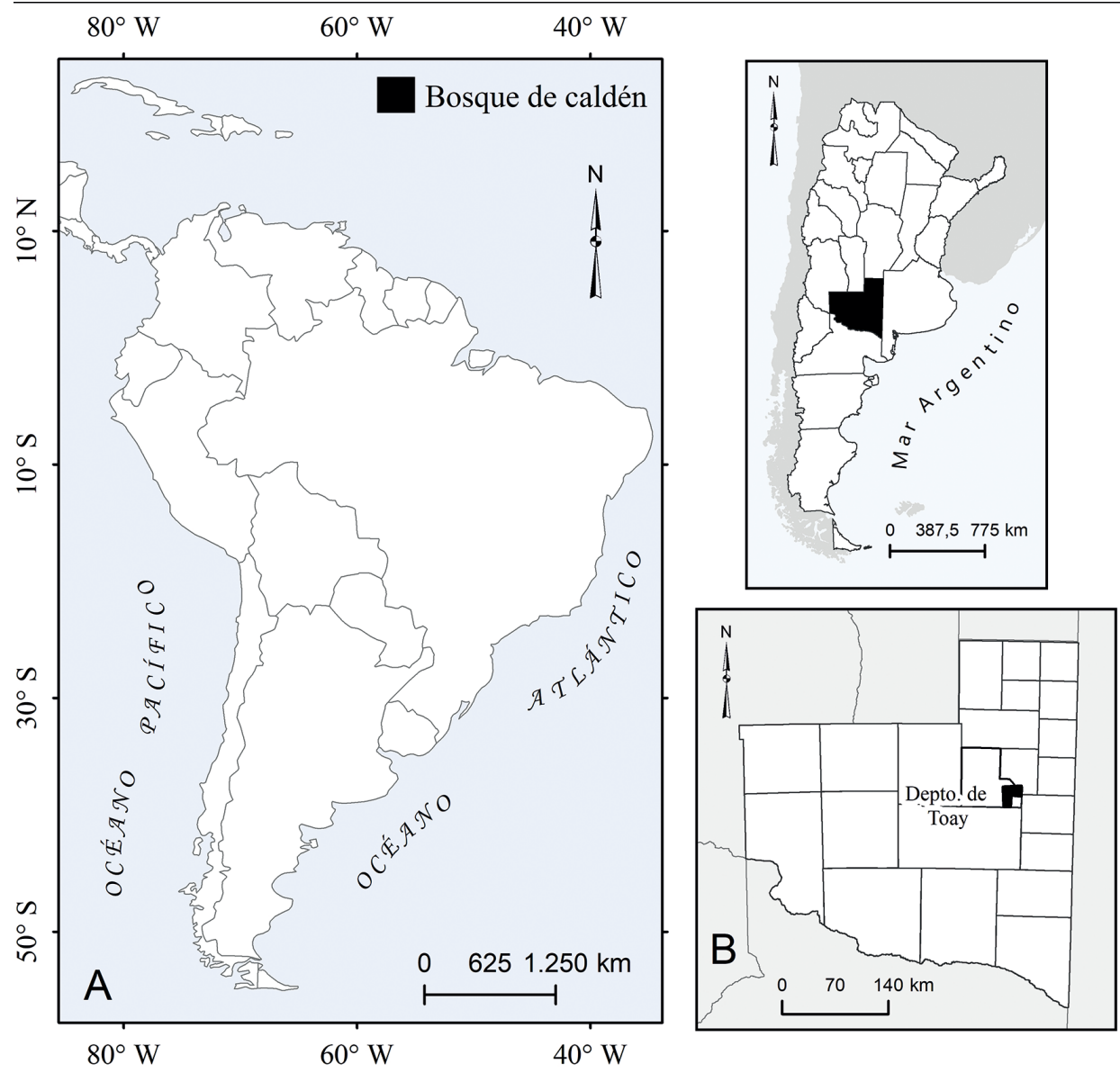

Fuente: Duval (2017).

Los datos fueron recolectados entre los meses de primavera y verano del año 2016. El muestreo utilizado fue el aleatorio estratificado en el sector del bosque. La reserva provincial posee, además, dos ambientes más, de médano y de salitral. Se aplicaron 10 transectos en banda de $100 \mathrm{~m}^{2}$ (50 x $2 \mathrm{~m}$ ). La orientación de los transectos fueron norte-sur y oeste-este.

Para conocer la cobertura de vegetación se utilizaron imágenes satelitales Landsat 8, cuyos sensores son: Operational Land Imager y el Sensor Térmico Infrarrojo. Estos poseen una resolución espacial de $30 \mathrm{~m}$ y 
una resolución temporal de 16 días, y fueron obtenidas mediante la página web del Servicio Geológico de Estados Unidos. Fueron seleccionadas cuatro imágenes, del año 2015, de todas las estaciones del año con el objetivo de observar la cobertura y la calidad de la vegetación mediante el cálculo del Índice de Vegetación Estandarizado (NDVI). Las fechas seleccionadas fueron 22 de enero, 22 de marzo, 19 de julio y 25 de noviembre, elección basada, además, por la disponibilidad de las imágenes, la reducción de la distorsión de las nubes y la dinámica estacional de la vegetación.

Se les realizaron correcciones radiométricas y atmosféricas con la finalidad de mejorar las anomalías que poseen las imágenes satelitales. En las imágenes primero se realizaron las transformaciones de los ND a valores de radiancia, decodificando los datos y estos a su vez fueron cambiados a valores de reflectancia al tope de la atmósfera (TOA). Finalmente, se realizó la corrección atmosférica proceso por el cual se eliminaron las distorsiones atmosféricas reduciendo el efecto de la atmósfera. Dicho proceso se llevó a cabo con el SIG Quantum Gis 2.8.7. A estas imágenes se les aplicó el NDVI, utilizando las bandas del infrarrojo cercano (banda 5) y la banda roja (banda 4).

Por otra parte, se obtuvieron diferentes índices de diversidad alfa que se observan en la tabla I. Además, se obtuvo el Índice de Valor de Importancia que mide el valor ecológico de cada especie en una comunidad vegetal y se obtiene mediante la suma de tres parámetros: dominancia, abundancia o densidad y frecuencia. Este índice se obtiene de la sumatoria de la frecuencia relativa, la densidad relativa y la dominancia relativa, cuyo resultado es igual a 300 . 
Valeria S. Duval, Graciela M. Benedetti, Alicia M. Campo. Fisonomía y diversidad del bosque secundario de Prosopis caldenia. Provincia de la Pampa, Argentina

Tabla 1. Índices de diversidad

\begin{tabular}{|c|c|c|}
\hline Índices & Fórmula & Explicación \\
\hline $\begin{array}{l}\text { [1] Índice de } \\
\text { Margalef }\left(\mathrm{D}_{\mathrm{Mg}}\right)\end{array}$ & $\begin{array}{l}\mathrm{D}_{\mathrm{Mg}}=\mathrm{S}-1 / \ln N \\
\mathrm{~S} \text { : número de especies. } N \text { : } \\
\text { número total de individuos. }\end{array}$ & $\begin{array}{l}\text { Se mide el número de especies } \\
\text { por número de individuos } \\
\text { especificados o la cantidad de } \\
\text { especies por área en una muestra. }\end{array}$ \\
\hline $\begin{array}{l}{[2] \text { Índice de }} \\
\text { Menhinick }\left(\mathrm{D}_{M n}\right)\end{array}$ & $\mathrm{D}_{M n}=\mathrm{S} / \sqrt{\mathrm{N}}$ & $\begin{array}{l}\text { Se basa en la relación entre el } \\
\text { número de especies y el número } \\
\text { total de individuos observados }\end{array}$ \\
\hline $\begin{array}{l}{[3] \text { Índice de }} \\
\text { dominancia de } \\
\text { Simpson }(\lambda)\end{array}$ & $\begin{array}{l}\lambda=\sum \mathrm{pi}^{2} \\
\text { pi: igual a la abundancia } \\
\text { proporcional de la especie } i .\end{array}$ & $\begin{array}{l}\text { Considera la representatividad de } \\
\text { las especies con mayor valor de } \\
\text { importancia, que es la dominante. }\end{array}$ \\
\hline $\begin{array}{l}\text { [4] índice de } \\
\text { diversidad de } \\
\text { Simpson (D) }\end{array}$ & $D=1-\lambda$ & $\begin{array}{l}\text { En la misma a medida que } \\
\text { el valor es cercano a } 1 \text { se } \\
\text { incrementa la diversidad y } \\
\text { disminuye la dominancia. } \\
\end{array}$ \\
\hline $\begin{array}{l}\text { [5] índice de } \\
\text { dominancia de } \\
\text { Berger Parker }\end{array}$ & $\begin{array}{l}\mathrm{d}=\mathrm{N} \text { máx. } / \mathrm{N} \\
\mathrm{N} \text { máx.: número de } \\
\text { individuos en la especie más } \\
\text { abundante. }\end{array}$ & $\begin{array}{l}\text { Este índice varía entre } 0 \text { y } 1 \text {, } \\
\text { cuanto más se acerca a } 1 \text { significa } \\
\text { que mayor es la dominancia y } \\
\text { menor la diversidad. }\end{array}$ \\
\hline $\begin{array}{l}\text { [6] Índice de } \\
\text { Shannon- Weaver } \\
\text { (H') }\end{array}$ & $\begin{array}{l}\mathrm{H}^{\prime}=-\sum[(\mathrm{pi}) \ln (\mathrm{pi})] \\
\text { pi: igual a la abundancia } \\
\text { proporcional de la especie } i .\end{array}$ & $\begin{array}{l}\text { Demuestra la relación entre la } \\
\text { abundancia y la riqueza y se } \\
\text { representa la uniformidad de } \\
\text { los valores de abundancia de las } \\
\text { especies. }\end{array}$ \\
\hline $\begin{array}{l}\text { [7] Índice de equidad } \\
\text { de Pielou (J') }\end{array}$ & $\begin{array}{l}\mathrm{J}^{\prime}=\mathrm{H}^{\prime} / \mathrm{H}^{\prime}{ }_{\text {máx. }} \\
\mathrm{H}^{\prime}{ }_{\text {máx.: }} \text { igual al logaritmo } \\
\text { neperiano de } \mathrm{S}\end{array}$ & $\begin{array}{l}\text { Mide la proporción de la } \\
\text { diversidad observada con relación } \\
\text { a la máxima diversidad esperada. }\end{array}$ \\
\hline
\end{tabular}

Fuente: Duval (2013).

\section{Resultados}

Fisonomía, usos y degradación del bosque de Prosopis caldenia

El caldenal posee formaciones fisonómicas distintas debido a la heterogeneidad del relieve, suelo y disturbios de origen antropogénicos. Teniendo en cuenta las denominaciones y características establecidas por diversos autores (Cisneros et al., 2002, Lerner, 2005, Zinda et al., 2005, Lencinas et al., 2006) se clasifica en: 
- $\quad$ Bosque abierto con pastizal (Figura 2A) o con arbustos (Figura 2B): el área basal promedio del árbol es de $5,6 \mathrm{~m}^{2} /$ ha y la cantidad es de aproximadamente 98 por ha. El bosque con pastizal se compone por el estrato arbóreo acompañado de gramíneas pertenecientes al estrato inferior (Albera, 2002, Lell, 2005, Dussart et al., 2011).

Figura 2. Fisonomías del bosque de caldén

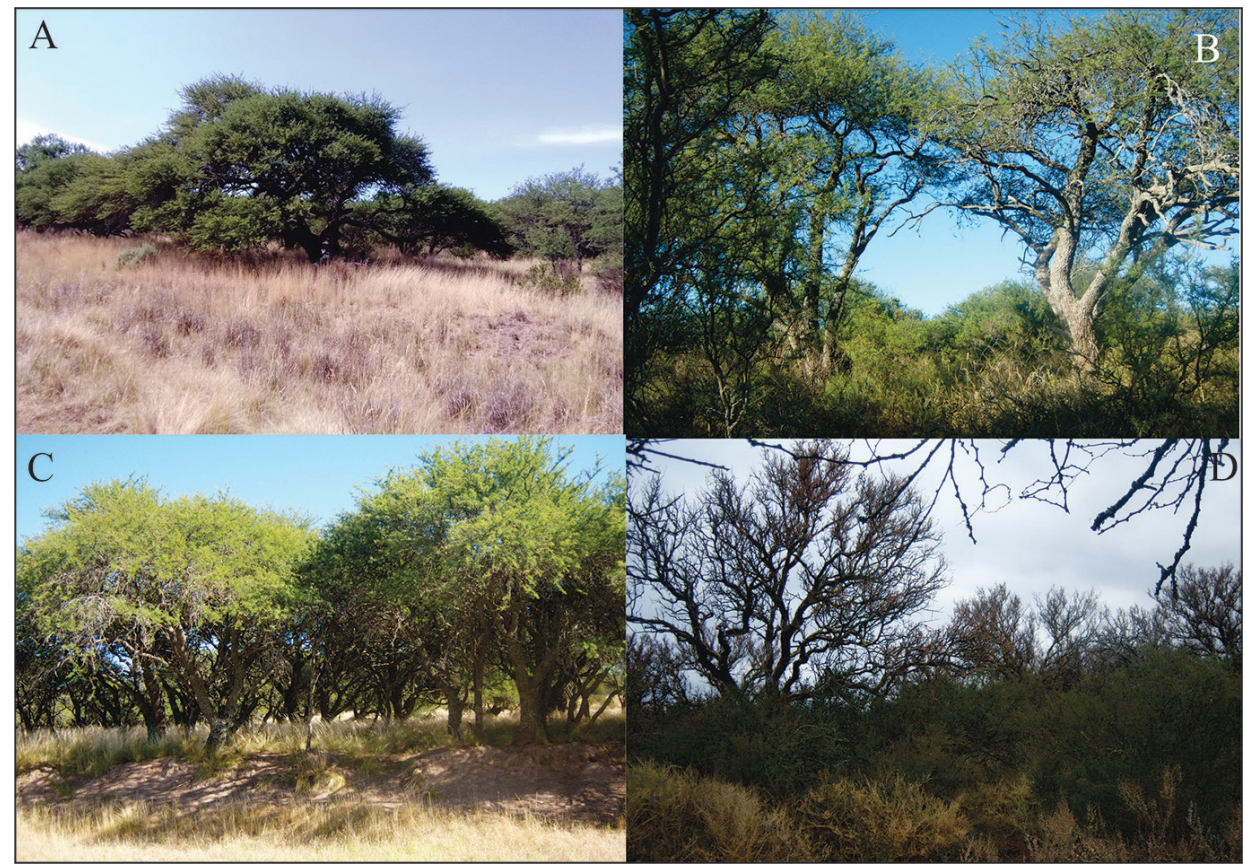

Bosque abierto con pastizal (A), bosque abierto con arbustos (B), bosque denso con pastizal (C) y bosque denso con arbustos (D).

Fuente: Duval (2017).

- $\quad$ Bosque denso con pastizal (Figura 2C) o arbustos (Figura 2D): el área basal total promedio es de $18 \mathrm{~m}^{2} /$ ha y el número de árboles es de 290 por ha. Generalmente, se lo encuentra acompañado por otras especies arbóreas y arbustivas. Se determina que este tipo de fisonomía es producto de la intervención antropogénica sobre el caldenal a través del desmonte, el uso del fuego y la actividad ganadera. 
La madera del caldén es resistente, con un peso específico medio y cuya vida útil en la intemperie es de 30 años. Su uso estuvo relacionado a los postes rurales, a los durmientes de las vías férreas, para la leña y como carbón. También se desmontaron grandes porciones de masa forestal para la práctica agropecuaria. Producto de esta valorización del recurso maderero y, en forma indirecta, del suelo pampeano para la agricultura y ganadería, el bosque fue reducido y degradado. En este sentido, este bosque, que se extendía al suroeste de la provincia en la provincia de Buenos Aires, actualmente quedó reducido a pequeñas porciones de tierra. En Córdoba, ocupaba una superficie de $30 \%$ y hoy solamente el 0,3\% de la superficie provincial. En San Luis, el bosque ocupaba el $11 \%$ del área del territorio provincial. En la actualidad, queda alrededor de un $8 \%$. La Pampa es el territorio con mayor extensión de este bosque y ocupaba el $24 \%$ de la provincia. El porcentaje de la masa forestal disminuyó actualmente a $11 \%$.

\section{Cobertura del bosque en la Reserva Provincial Parque Luro}

La Reserva Provincial Parque Luro, en general, posee una elevada cobertura vegetal y de gran vigorosidad (Figura 3). Se observó que, en la imagen de verano del año 2015, los valores del NDVI se encontraron por encima de 0,6 en más del $50 \%$ del área protegida. El agua de la laguna, representado en color rojo, significa ausencia de vegetación mientras que los verdes son áreas con vegetación vigorosa y de amplia cobertura con valores superiores a 0,9. Estas zonas se localizaron en el noroeste y en el sureste de la reserva. Los NDVI entre 0 a 0,5 se registraron en los alrededores de la laguna intermitente, cuya vegetación es halófila. Durante la estación térmica invernal se observaron valores inferiores en relación con las otras estaciones del año que responde a las plantas perennifolias. Predominó la categoría de 0,41 a 0,6 y en segundo lugar de 0,61 a 0,8 .

En el caso de las estaciones intermedias, otoño y primavera se observó una ausencia de la categoría de 0,11 a 0,2. En el otoño el índice adquirió su máximo en el noroeste de la reserva y se expandió en superficie la segunda categoría de 0,21 a 0,4. En la imagen de la primavera se observó que los valores medios de este índice se expandieron en casi toda la reserva. Este hecho coincidió con el período de mayor actividad vegetal asociado a la época del año y con el mayor registro de precipitaciones. En comparación con la imagen de verano, la categoría 0,61 a 0,8 tuvo la mayor cobertura de 
la imagen. En contraposición se redujo en la primavera la superficie de los valores de 0,8 a 1, alcanzando su máximo en 0,81 fuera de los límites de la reserva. La mayor densidad y vigorosidad se produjo durante el período de primavera, asociado al período de mayores precipitaciones. No obstante, la estación térmica estival presentó los valores más elevados de NDVI en relación con las otras estaciones. Los valores negativos implicaron ausencia de vegetación y se correspondieron con el cuerpo lagunar.

Figura 3. NDVI según las estaciones térmicas en la Reserva Provincial Parque Luro
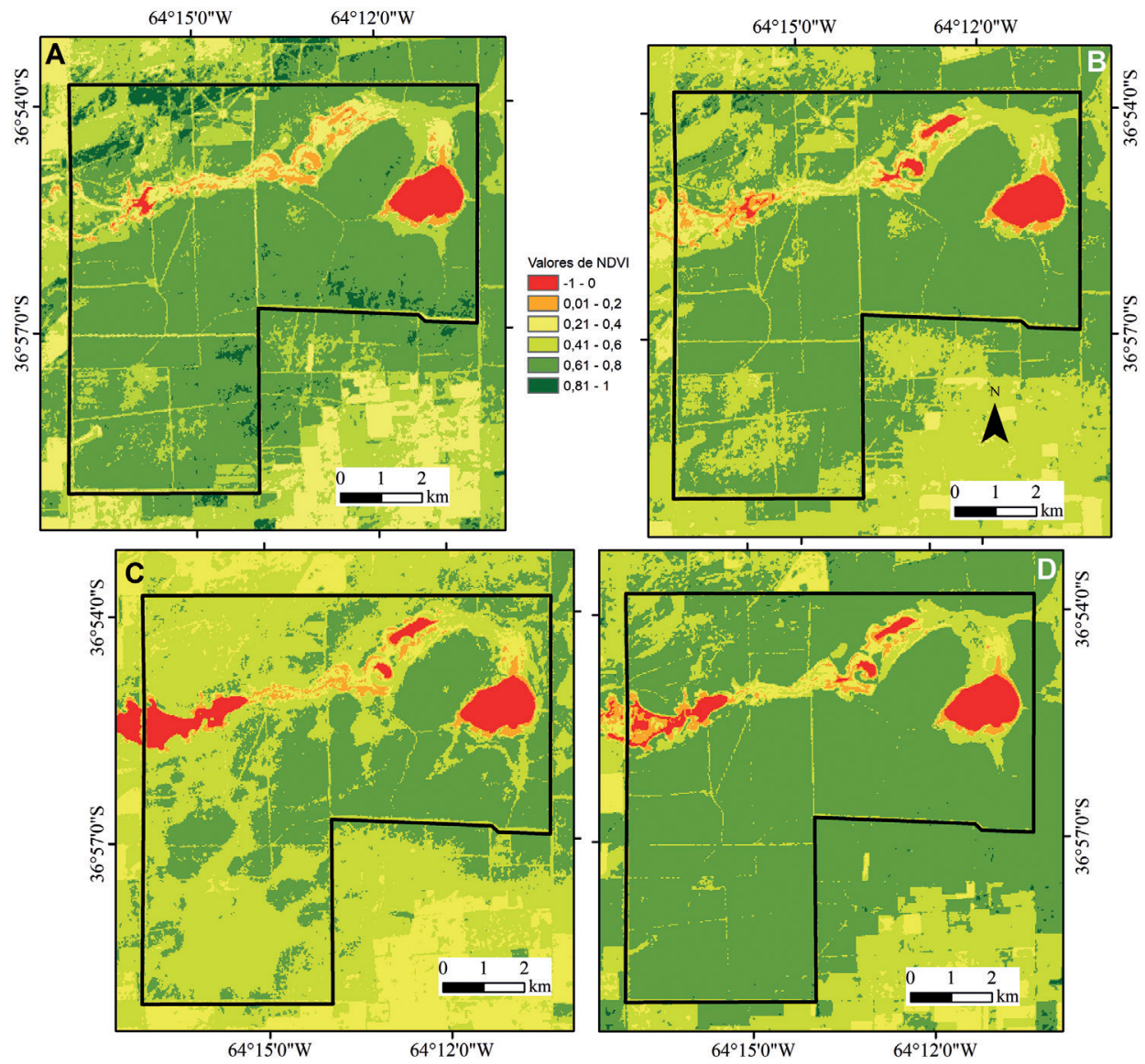

Referencias: A. Verano, B. Otoño, C. Invierno y D. Primavera.

Fuente: Duval (2017) sobre la base de Google Earth Pro®. 
Valeria S. Duval, Graciela M. Benedetti, Alicia M. Campo. Fisonomía y diversidad del bosque secundario de Prosopis caldenia. Provincia de la Pampa, Argentina

\section{Diversidad del caldenal}

De la aplicación de la metodología de Cámara Artigas y Díaz del Olmo (2013) se identificaron 397 individuos vegetales correspondientes a 15 especies y 9 familias. La familia Fabaceae fue la de mayor representación con 5 especies, seguida de Solanaceae y Asteranceae con 2 especies cada una y Chenopodiaceae, Rhamnaceae, Verbenaceae, Santalaceae y Ephedraceae con 1 especie.

En el transecto 1 (Figura 4) fueron identificados 60 individuos, pertenecientes a 8 familias y 9 especies. Las especies de mayor abundancia fueron el molle negro con 19 individuos, luego el piquillín con 12 y el yaoyín con 11. Se observó en el diagrama de burbujas que la mayor cantidad de los individuos se localizan en la segunda mitad del transecto. El azhar del monte y la zampa crespa (Atriplex undulata) se encuentran concentradas en un mismo sitio mientras que, la yerba de oveja (Baccharis ulicina) y el molle negro se hayan dispersos en todo el transecto.

Figura 4. Diagrama de burbujas del transecto 1.

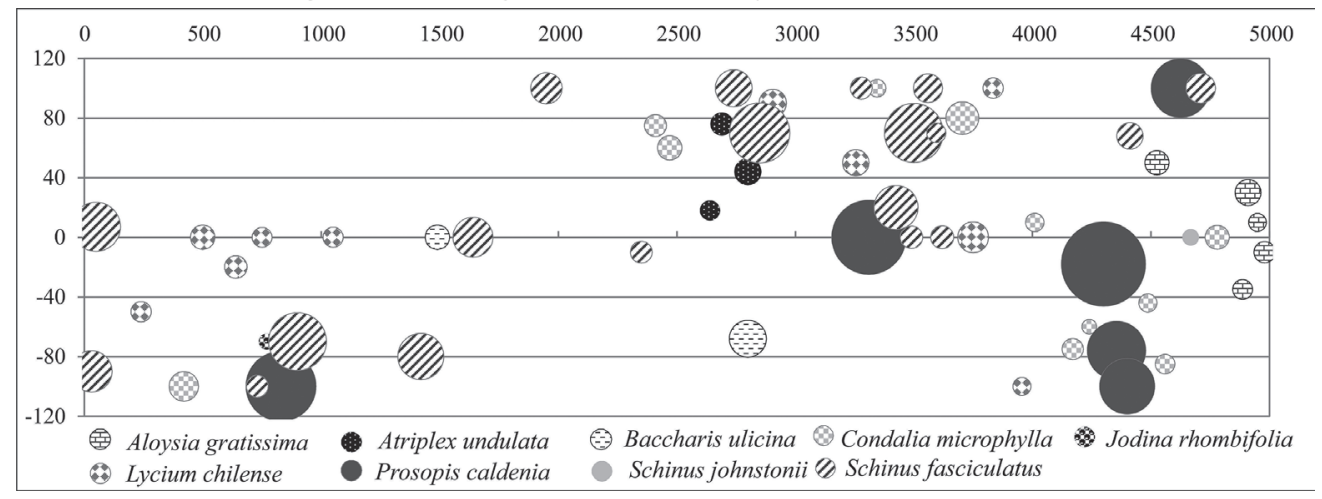

Fuente: Duval (2017).

Los estratos existentes, según el Diagrama Ecodinámico de RiquezaEstructura-Cobertura (Figura 5), son el herbáceo (h) y subarbustivo (s_ab) constituida por 1 especie, el arbustivo (ab) con 8 especies, el arbustivo alto (ab_a) con 3 especies, el arbóreo bajo (A1) por 1 especie y el arbóreo medio (A2) por 2 especies. Los estratos s_ab $(0,2 \%)$ y h $(5,9 \%)$ y A $1(6,8$ $\%)$ presentan cobertura abierta a semiabierta. En el ab (18, $3 \%)$ y el ab_a $(31,7 \%)$ la formación es menos abierta mientras que en el A2 (37\%) es 
más cerrada. El molle negro $(34,2)$, el caldén $(19,6)$ y el piquillín $(15,6)$ presentaron un elevado índice de valor de importancia.

Figura 5. Diagrama Ecodinámico de Riqueza-Estructura-Cobertura del transecto 1 .

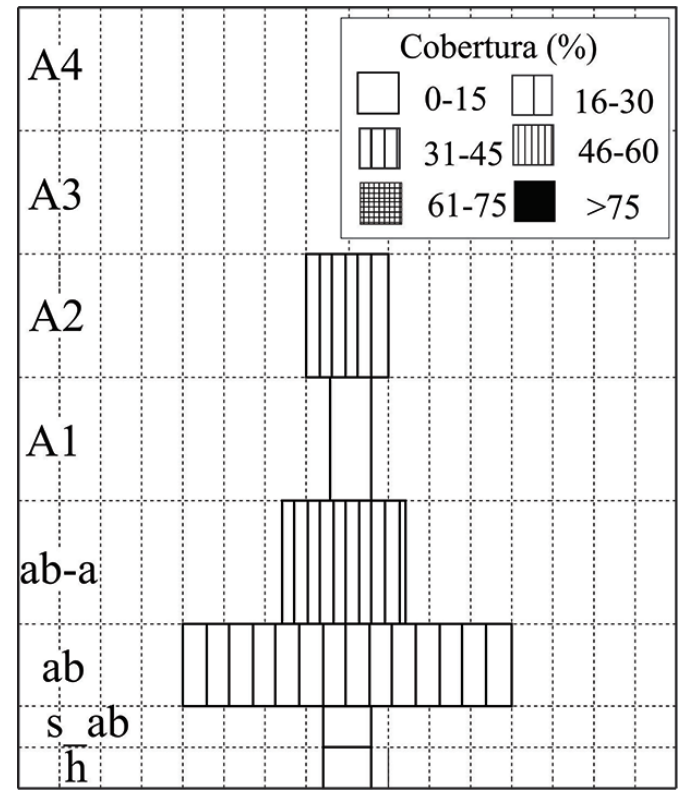

Fuente: Duval (2017).

En el transecto 2 fueron identificados 54 individuos, pertenecientes a 7 familias y 9 especies. Las especies de mayor abundancia fueron el molle negro con 14 individuos y el yaoyín y el piquillín con 8 . En el diagrama de burbujas se observa que el molle negro se distribuyó por todo el transecto al igual que la zampa crespa. Si bien, el caldén tuvo pocos ejemplares en el transecto, su cobertura fue superior a las de las otras especies. Los estratos representados fueron 5 desde el s_ab hasta el A2. En el estrato s_ab se relevaron 3 especies con una cobertura muy abierta (2,02\%), fueron 6 especies en el ab con una cobertura de $18 \%$, en el ab-a fueron 3 especies con una cobertura más cerrada que el anterior estrato. La misma cobertura tuvo el estrato A1 con 2 especies, y el arbóreo A2 contó solo con una especie y su cobertura fue abierta $(19 \%)$. El molle negro $(36,6)$, el caldén $(15,4)$ y el piquillín $(11,3)$ presentaron un elevado índice de valor de importancia. 
Valeria S. Duval, Graciela M. Benedetti, Alicia M. Campo. Fisonomía y diversidad del bosque secundario de Prosopis caldenia. Provincia de la Pampa, Argentina

En el transecto 3 fueron identificados 39 individuos, pertenecientes a 7 familias y 8 especies. Las especies de mayor abundancia fueron azhar del monte con 13 individuos, luego el algarrobo con 8 y el piquillín con 6. En el diagrama de burbujas se muestra que la mayor cantidad de estos individuos se localizaron en la primera mitad del transecto. Los individuos de algarrobo se hallaron centrados entre sí mientras que los de piquillín estuvieron más dispersos en el transecto. Las alturas variaron entre $60 \mathrm{~cm}$ a $700 \mathrm{~cm}$. Los estratos representados son 5 desde el h hasta el A2. La mayor cobertura se observa en el estrato A2, siendo de 36,2\% correspondiente al algarrobo. Los de menor porcentaje de cobertura son el h, s_ab y A1 con un porcentaje menor de 15 . Las de menor porcentaje de IVI fueron la sombra de toro con $2 \%$ y la barba de chivo con $4,4 \%$.

En el transecto 4 fueron identificados 28 individuos, pertenecientes a 5 familias y 6 especies. Las especies de mayor abundancia fueron el azhar del monte y el piquillín. En el diagrama de burbujas los individuos están dispersos por todo el transecto. En general, los ejemplares de azhar del monte se encontraron en el sector final y en grupo. Otras especies como el piquillín poseían un grado más bajo de socialización entre su misma especie y por ende estaban separados. Exceptuando por el caldén, el resto de las plantas eran arbustivas. Las alturas variaron entre $60 \mathrm{~cm}$ en a $700 \mathrm{~cm}$. Los estratos representados fueron 5 desde el s_ab hasta el A2. La mayor cobertura se observó en los estratos ab_a (28,4\%) perteneciente a la especie. Los de menor porcentaje de cobertura fueron el h, s_ab y A1 con menos del $6 \%$.

En el transecto 5 fueron identificados 29 individuos, pertenecientes a 5 familias y 6 especies. Se reconocieron dos especies arbóreas, el caldén y el algarrobo, ambos de la familia Fabaceae. Las especies de mayor abundancia fueron el caldén y el azhar del monte con 11 y 8 individuos. El caldén $(48,6)$ y el azhar del monte $(20,7)$ presentaron un elevado índice de valor de importancia. Las de menor IVI fueron piquillín de víbora (Lycium gilliesianum) $(3,3)$ y el molle negro $(7,5)$. Azhar del monte se socializó en pequeños grupos mientras que los árboles como el caldén tendieron a estar dispersos entre sí. Las alturas variaron entre $61 \mathrm{~cm}$ a $600 \mathrm{~cm}$. No se relevaron especies pertenecientes al estrato $\mathrm{h}$ y el s_ab solo poseía un individuo. El ab presentó 5 especies y tanto el ab_a como el A1 contaron con 2 especies. En el A2 se encontró una especie. En cuanto a su cobertura, el A1 
es el que presentó mayor porcentaje y, por lo tanto, es de tipo semicerrado. El estrato ab_a poseía más del $16 \%$, lo cual muestra una cobertura semiabierta y, finalmente, el resto de los estratos presentaron una gran dispersión entre los individuos vegetales.

En el transecto 6 fueron identificados 32 individuos, pertenecientes a 5 familias y 7 especies. El caldén y el algarrobo son representantes del biotipo arbóreo mientras que el resto de las especies son del arbustivo. La especie de mayor abundancia fue molle negro seguida del caldén con 9 y 8 individuos. En el diagrama de burbujas se observó que los individuos de algarrobo se encontraban en el sector medio y final del transecto, lo cual demuestra que poseen un comportamiento de sociabilidad superior a otras especies como piquillín, cuyos individuos se dispersan en forma individual. El gráfico de estructura mostró que no hay representantes de los dos primeros estratos ( $\mathrm{h}$ y s_ab) mientras que el ab presentó mayor cantidad de especies con 6. El ab_a fue el de mayor cobertura superando el $61 \%$ seguido del ab con $25 \%$.

En el transecto 7 fueron identificados 38 individuos vegetales, 6 especies y 5 familias. La especie de mayor abundancia fue el molle negro con 13 y el yaoyín con 10 individuos. El caldén se encontró agrupado en la segunda mitad del transecto y su cobertura es mayor a la de las demás especies, el piquillín y el molle negro se encontraban dispersos y se distribuyeron sobre todo el transecto. Los estratos h y s_ab no se encontraban representados por ninguna de las especies. Los que poseen mayor cantidad de especies es el ab_a con 5, seguido del arbustivo con 4. En cuanto a la cobertura, el ab y el A2 son los que poseían mayor porcentaje, 34 y 42, respectivamente.

En el transecto 8 fueron identificados 42 individuos, pertenecientes a 4 familias y 6 especies. El molle negro y el yaoyín son las especies más numerosas con 18 y 17 individuos, respectivamente. Del relevamiento se obtuvo también las alturas que variaran de $30 \mathrm{~cm}$ a $650 \mathrm{~cm}$. Los estratos representados fueron el herbáceo, el s_ab, el ab, el ab_a y el ab. El que tuvo mayor cobertura fue el arbustivo, cuyo porcentaje fue cercano al $50 \%$, es decir, era semicerrado. También el ab_a poseía una cobertura cercana al $40 \%$ y los estratos más bajos como el h y el s_ab presentaron una cobertura abierta. No hubo presencia de especies en los estratos superiores al ab 1. 
Valeria S. Duval, Graciela M. Benedetti, Alicia M. Campo. Fisonomía y diversidad del bosque secundario de Prosopis caldenia. Provincia de la Pampa, Argentina

En el transecto 9 (Figura 6) fueron identificados 41 individuos, pertenecientes a 3 familias y 5 especies. El caldén y el molle negro eran las especies más numerosas con 15 y 12 individuos, respectivamente. La de menor abundancia fue el piquillín de víbora con 2 ejemplares. En el diagrama de burbujas se observaron las alturas que variaron de $50 \mathrm{~cm}$ a 450 $\mathrm{cm}$ y la ausencia del estrato herbáceo. Estuvieron presentes los estratos $\mathrm{s}_{-}$ ab, ab, ab_a, A1y A2. En general, los dos primeros tuvieron una cobertura muy abierta mientras que los estratos superiores eran de tipo semicerrado, principalmente, el arbóreo medio (Figura 7).

Figura 6. Diagrama de burbujas del transecto 9 en la Reserva Provincial Parque Luro.

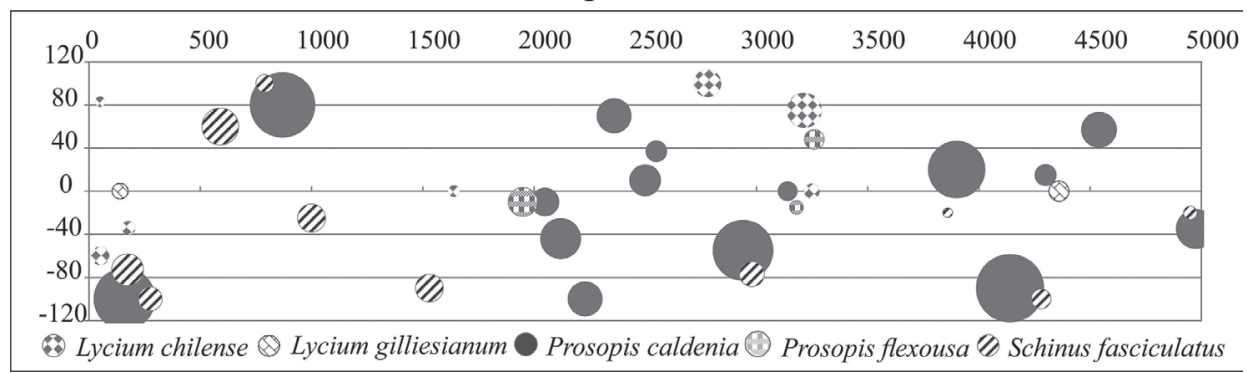

Fuente: Duval (2017).

Figura 7. Diagrama Ecodinámico de Riqueza-Estructura-Cobertura del transecto 9 .

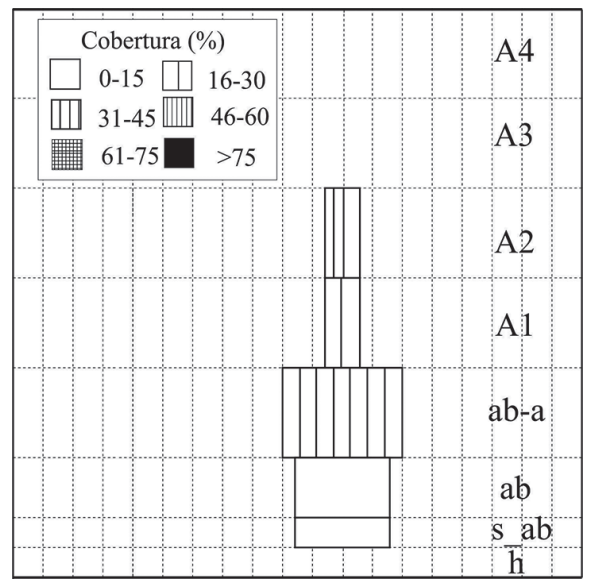

Fuente: Duval (2017). 
En el transecto 10 (Figura 8) fueron identificados 34 individuos, pertenecientes a 7 familias y 9 especies. El caldén y el molle negro fueron las especies más numerosas con 8 y 6 individuos, respectivamente. Las menos abundantes fueron la yerba de oveja y piquillín de víbora con 2 ejemplares. El estrato herbáceo y subarbustivo estuvieron ausentes mientras que el arbustivo alto fue el de mayor cobertura con más de $40 \%$, lo cual demostró que era semicerrado. Presentó un estrato arbóreo bajo y medio semiabierto y un estrato subarbustivo abierto. En los estratos arbóreos se observó 1 especie en cada una, en el medio y bajo, en el arbustivo y arbustivo alto fueron 6 las especies en cada uno (Figura 9).

Figura 8. Diagrama de burbujas del transecto 10 en la Reserva Provincial Parque Luro.

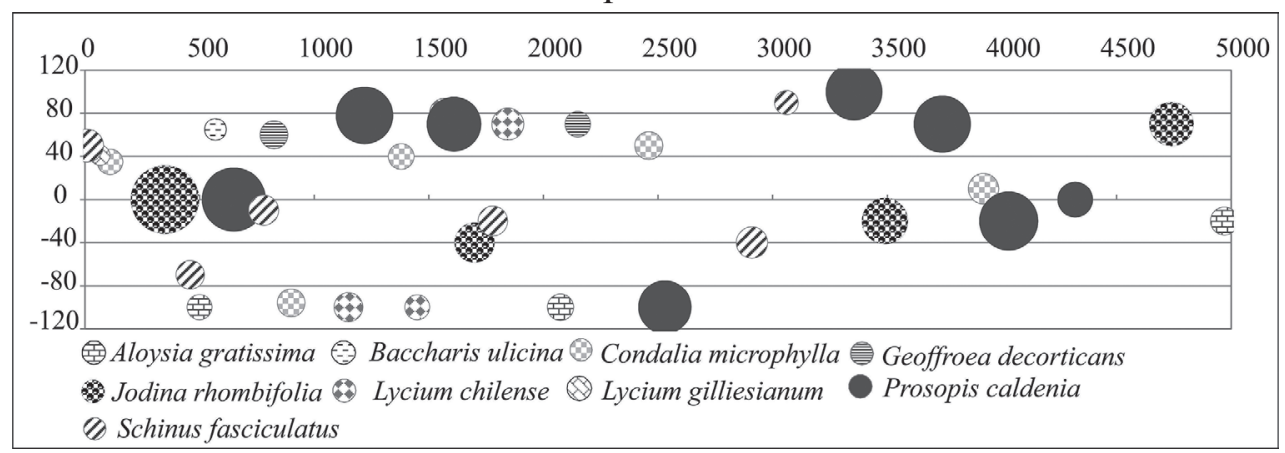

Fuente: Duval (2017). 
Valeria S. Duval, Graciela M. Benedetti, Alicia M. Campo. Fisonomía y diversidad del bosque secundario de Prosopis caldenia. Provincia de la Pampa, Argentina

Figura 9. Diagrama Ecodinámico de Riqueza-Estructura-Cobertura del transecto 10 .

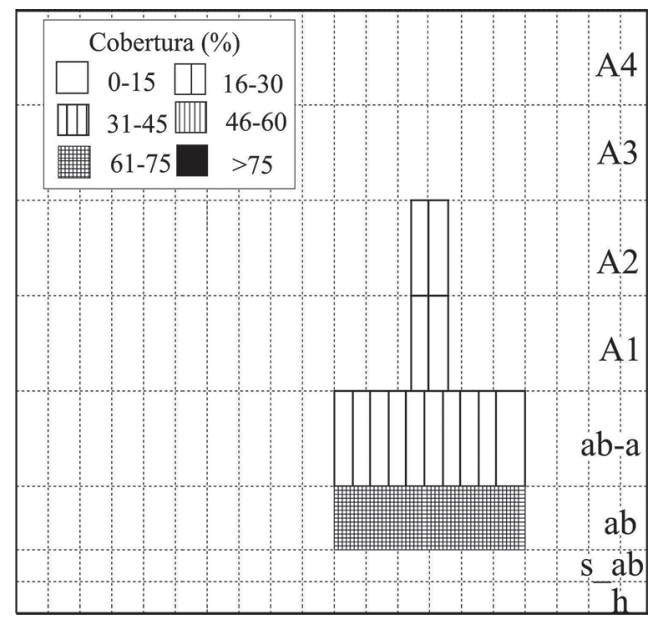

Fuente: Duval (2017).

Los resultados arrojados por la unión de los 10 transectos determinaron que en general la comunidad poseía una riqueza específica media. La [1] presentó valores de entre 1,07 y 2,26 y la [2] de 0,78 a 1,54. En ambos casos se observó que la mayor riqueza florística estuvo en el transecto 10 y la menor en el 9. El [3] presentó en todos los transectos valores bajos, lo cual implica que la dominancia es baja. La [4] reveló que la diversidad de la comunidad es media teniendo en la mayoría de los transectos valores aproximados a 0,8 exceptuando el transecto 8 que presentó 0,64 .

El [5] dio a conocer valores bajos por lo cual la vegetación de las parcelas es menos dominante. El [6] mostró valores medios, es decir, las especies se encuentran medianamente representadas en los transectos. El transecto 10 es el que tuvo una mayor representación de especies de igual forma. Como resultado presentaron en su mayoría una diversidad media. En el [7] se observaron valores cercanos a 1, exceptuando en el 8 que tiene 0,69 . Esto demuestra que todas las especies estaban igualmente abundantes en la muestra. Como conclusión, los transectos mostraron una diversidad media, una alta equidad y una dominancia baja. Los valores de los índices se presentan en la tabla II. 
Tabla 1I. Registro de los índices de diversidad alfa en la Reserva Provincial Parque Luro

\begin{tabular}{|c|c|c|c|c|c|c|c|}
\hline Transecto & {$[\mathbf{1}]$} & {$[\mathbf{2}]$} & {$[\mathbf{3}]$} & {$[\mathbf{4}]$} & {$[\mathbf{5}]$} & {$[\mathbf{6}]$} & [7] \\
\hline 1 & 1,9 & 1,2 & 0,2 & 0,8 & 0,3 & 1,8 & 0,8 \\
\hline 2 & 2 & 1,2 & 0,2 & 0,8 & 0,3 & 2 & 0,9 \\
\hline 3 & 1,9 & 1,3 & 0,2 & 0,8 & 0,3 & 1,8 & 0,9 \\
\hline 4 & 1,5 & 1,1 & 0,2 & 0,8 & 0,4 & 1,6 & 0,9 \\
\hline 5 & 1,5 & 1,1 & 0,3 & 0,7 & 0,4 & 1,5 & 0,9 \\
\hline 6 & 1,7 & 1,2 & 0,2 & 0,8 & 0,3 & 1,7 & 0,9 \\
\hline 7 & 1,4 & 1 & 0,2 & 0,8 & 0,3 & 1,6 & 0,9 \\
\hline 8 & 1,3 & 0,9 & 0,4 & 0,6 & 0,4 & 1,2 & 0,7 \\
\hline 9 & 1,1 & 0,8 & 0,3 & 0,7 & 0,3 & 1,4 & 0,9 \\
\hline 10 & 2,3 & 1,5 & 0,2 & 0,9 & 0,2 & 2 & 0,9 \\
\hline
\end{tabular}

[1] Índice de Margalef, [2] Índice de Menhinick, [3] Índice de dominancia de Simpson, [4] Índice de diversidad de Simpson, [5] índice de dominancia de Berger Parker, [6] Índice de Shannon- Weaver y [7] índice de equidad de Pielou.

Fuente: Duval (2017).

En el estrato arbóreo se representa el caldén que estuvo presente en 9 de los 10 transectos y tuvo valores de Índice de Valor de Importancia por encima del $15 \%$ en 7 parcelas. El mayor valor de IVI fue registrado en la parcela 5, y en esta especie. El algarrobo estuvo presente en 6 de los 10 transectos, mientras que la sombra de toro en 5 y chañar en 3 . En el estrato arbustivo, el molle negro fue la especie con mayor frecuencia ya que se presentó en la totalidad de los stands y superó el $15 \%$ del IVI en 7 transectos. El azhar del monte y el yaoyín se presentaron en 8 de los 10 transectos y en 3 de ellos el valor fue mayor a $15 \%$. El piquillín tuvo una importancia media en los 7 transectos en los cuales apareció. El resto de los arbustos (Senecio subulatus, Atriplex undulata, Baccharis ulicina, Caesalpinia gilliesii, Lycium gilliesianum y Schinus johnstonii) tuvo una presencia baja en la muestra y los valores obtenidos fueron bajos.

\section{El marco legal vinculado a la restauración del caldenal}

En 2011 se sancionó la ley 2624, de Ordenamiento Territorial de Bosques Nativos en la provincia de La Pampa. En esta ley se definieron la autoridad de aplicación, las categorías de conservación y las infracciones 
y sanciones por su incumplimiento. Entre las categorías se presentaron las zonas categoría I (rojo), las de categoría 2 (amarillo) y las de categoría III (verde). En la provincia hay casi 4 millones de hectáreas pertenecientes al bosque de caldén y de esa superficie el $1 \%$ se encuentra bajo la categoría I, el $76 \%$ corresponde a la categoría II y el $23 \%$ a la categoría III.

La Pampa recibió de la Nación una inversión de dinero para el desarrollo de investigaciones sobre el bosque de caldén. La finalidad fue conocer el estado actual del bosque y establecer acciones para su enriquecimiento, restauración y conservación. La Reserva Provincial Parque Luro pertenece a la categoría I, en la cual se pueden realizar actividades de protección, mantenimiento y recolección que contribuyan a la restauración del bosque de caldén sin afectar la integridad del ecosistema. En los últimos años, se realizaron acciones en relación con la conservación, entre ellas, se puede mencionar las quemas prescriptas que contribuyen a disminuir el riesgo de incendios en el área y la reintroducción de fauna autóctona (Bosque Pampeano, 2015). La información generada sobre el estado del bosque en la reserva, en específico, es una herramienta para avanzar con la gestión enfocada a la restauración del bosque de caldén.

\section{Conclusión}

Originariamente, este bosque poseía una forma similar a una sabana con árboles bien desarrollados, de gran altura y dispersos y una cubierta de herbáceas abundantes. Por las actividades realizadas desde fines del siglo XIX, tales como la deforestación y la ganadería, la fisonomía y estructura del bosque se modificó. Esto podría explicar el hecho de que el Índice de Valor de Importancia del caldén fuera superior a $15 \%$ en 7 de los 10 transectos y no en su totalidad. De esta forma, avanzan otras especies del estrato arbustivo como Schinus fasciculatus con mayor presencia en la totalidad de los transectos y con valores superiores al $15 \%$ en 6 de los 10 transectos. El porcentaje de cobertura muestra una distribución espacial semiabierta, comprobada en los Diagramas Ecodinámicos de RiquezaEstructura-Cobertura de los transectos. Los estratos presentes fueron el herbáceo, el subarbustivo, el arbustivo, el arbustivo alto, el arbóreo bajo y el arbóreo medio. De la contabilización y suma de las especies en cada estrato y transecto se comprobó que el rango de altura más frecuente fue 
de 61 a $150 \mathrm{~cm}$, perteneciente al estrato arbustivo, el arbustivo alto de 151 a $350 \mathrm{~cm}$ y el arbóreo bajo de 351 a $500 \mathrm{~cm}$.

Para evaluar la biodiversidad vegetal, se seleccionaron formaciones vegetales terrestres con fisonomía uniforme y en sectores con vegetación homogénea. De la aplicación de la metodología de Cámara Artigas y Díaz del Olmo (2013) se identificaron 397 individuos vegetales correspondientes a 15 especies y 9 familias. La familia Fabaceae fue la de mayor representación con 5 especies, seguida de Solanaceae y Asteranceae con 2 especies cada una y Chenopodiaceae, Rhamnaceae, Verbenaceae, Santalaceae y Ephedraceae con 1 especie.

Como síntesis de la muestra, se reconoce que el biotipo representativo del caldenal es el arbóreo con una altura promedio entre 10 a $12 \mathrm{~m}$. La periodicidad de la vegetación es en general caducifolia, excepto algunas caméfitas como el piquillín. Se pudo reconocer una fisonomía semiabierta con arbustos que dista del bosque prístino de caldén. Esta formación se ve actualmente reducida y en los pocos espacios donde tiene mayor desarrollo en superficie se encuentra modificada, cuestión que se observa en la mayor proporción de arbustos.

Este tipo de metodologías es esencial para reconocer las características propias de la vegetación de forma más detallada. Realiza un aporte de los elementos y variables que posee el paisaje vegetal e incorpora información cuantitativa y cualitativa esencial para la planificación de estos espacios que tienen como objetivo la preservación del ecosistema. Por otra parte, el conocimiento generado sobre esta vegetación es relevante para conocer su estado y analizar los cambios en su fisonomía de acuerdo las transformaciones humanas. La información generada en este trabajo será un instrumento para establecer medidas de acción y restauración del bosque de caldén bajo la ley de ordenamiento del bosque nativo de la provincia.

\section{Agradecimientos}

El presente trabajo se desarrolló en el marco del proyecto Geografía Física aplicada al estudio de la interacción sociedad-naturaleza. Problemáticas a diferentes escalas témporo-espaciales. Dirigido por la Dra. Alicia María Campo. Secretaría de Ciencia y Tecnología, Universidad Nacional del Sur.amcampo@uns.edu.ar 
Valeria S. Duval, Graciela M. Benedetti, Alicia M. Campo. Fisonomía y diversidad del bosque secundario de Prosopis caldenia. Provincia de la Pampa, Argentina

\section{Referencias}

Albera, H. (2002). Bosque de caldén en la provincia de La Pampa. Gobierno de la Provincia de Córdoba. $1^{\text {ra }}$ Reunión Nacional para la Conservación de la Caldenia Argentina. Córdoba, Argentina: Agencia Córdoba. (pp. 31-39).

Bogino, S. M. (2006). El bosque de caldén en la provincia de San Luis: situación actual y estrategias alternativas de manejo. En: Kairós, Revista de Temas Sociales, 17, 1-7.

Benlloch, I. y Yetano, M. (1989). El estudio de la vegetación en Geografía. En: Geographicalia, 26, 165-174.

Bosque Pampeano. (2015). El bosque en Parque Luro. Recuperado de http://www.bosquepampeano.org/index.php/planes/ novedades/342-el-bosque-en-parque-luro

Cabrera, A. (1976). Regiones fitogeográficas argentinas. Tomo II. Enciclopedia argentina de agricultura y jardinería. Buenos Aires, Argentina: Acme. (pp. 1-90).

Cámara, R. y Díaz del Olmo, F. (2013). Muestreo en transecto de formaciones vegetales de fanerófitos y caméfitos (I): fundamentos metodológicos. En: Estudios Geográficos, 74(274), 67-88.

Cisneros, J. M., Nuñez, C., Cantero, O., Degioanni, J., Plevich, A., Cabido, O., Petryna, L. y Amuchastegui, A. (2002). Caldenia cordobesa: Una síntesis florística y ambiental. En: Primera Reunión para la conservación de la Caldenia Argentina. Córdoba, Argentina: Agencia Córdoba. (pp. 18-20).

Dussart E., Chirino, C., Morici, E. y Peinetti, R. H. (2011). Reconstrucción del paisaje del caldenal pampeano en los últimos 250 años. Quebracho, 19(1,2) 54-65.

Lell, J. D. (2005). El caldenal: una visión panorámica del mismo enfatizando en su uso. En: Ecología y manejo de los bosques de Argentina. (pp. 1-18). La Plata, Argentina: Editorial de la Universidad Nacional de La Plata.

Lencinas J. D., Chauchard, L. y Grosfeld, J. (2006). Primer inventario nacional de bosques nativos segunda etapa. Inventario de campo de la región espinal distritos caldén y ñandubay. Buenos Aires, Argentina: Secretaría de Ambiente y Desarrollo Sustentable de la Nación. 
Lerner, P. (2005). El caldenal: dinámica de poblaciones de caldén y procesos de expansión de leñosas en pastizales. Ecología y manejo de los bosques de Argentina. La Plata, Argentina: Editorial de la Universidad Nacional de La Plata. (pp. 1-15).

Lewis J. P., Prado, D. E. y Barberis, I. (2004). Los remanentes de bosques del Espinal en el este de la provincia de Córdoba. La situación ambiental Argentina 2005. (pp. 254-260).

Medina, A. (2007). Reconstrucción de los regímenes de fuego en un bosque de Prosopis caldenia, provincia de La Pampa, Argentina. En: Bosque, 28(3) 234-240.

Medina, A. (2008). Cicatrices de fuego en el leño de Prosopis caldenia en Luán Toro, provincia de La Pampa, Argentina. En: Bosque, 29(2), 115-119.

Moreno, C. (2001). Métodos para medir la biodiversidad. Zaragoza, España: La Sociedad Entomológica Aragonesa.

Sala, M. y Batalla, R. (1996). Teoría y métodos en Geografía Física. Madrid, España: Síntesis.

Zinda, R., Adema, E. y Rucci, T. (2005). Relevamiento fisonómico de la vegetación del área del caldenal. Instituto Nacional de Tecnología Agropecuaria Angüil. Recuperado de: https://inta.gob.ar/sites/default/files/script-tmp-publi60.pdf 